\title{
Compound odontoma associated with mandibular impacted permanent central incisor: a case report
}

\author{
Seref Ezirganli, DDS, $\mathrm{PhD}^{\mathrm{a}}$, Ufuk Tasdemir, DDS, $\mathrm{PhD}^{\mathrm{b}}$, Ugur Gurer, DDS, $\mathrm{PhD}^{\mathrm{c}}$ \\ ${ }^{a}$ Bezm-i Alem University, Faculty of Dentistry, Department of Oral and Maxillofacial Surgery, İstanbul, Turkey. \\ ${ }^{\mathrm{b}}$ Cumhuriyet University, Faculty of Dentistry, Department of Oral and Maxillofacial Surgery, Sivas, Turkey. \\ ${ }^{\mathrm{c}}$ Private practice, Dental Clinic, Sivas, Turkey.
}

Received: 05 May $2011 \quad$ Accepted: 15 August 2011

\begin{abstract}
Odontomas are the most common benign odontogenic tumors that are hamartomas composed of various dental tissues, and there are two types, complex and compound. Compound odontomas are more prevalent than complex odontomas and consist of many teeth-like structures. Most of such lesions are asymptomatic. These lesions are generally diagnosed by routine radiological examination. The compound type is generally found in the anterior region of the maxilla. The etiology of these lesions has not been precisely explained. If there is absence of any contraindication, the treatment for odontomas is surgical excision.

This article describes a case of compound odontoma associated with impacted central mandibular right permanent incisor in a 12-year-old female due to trauma. The odontoma was surgically removed with an impacted central incisor.
\end{abstract}

Keywords: Compound odontoma, mandible, odontogenic tumor.

\section{INTRODUCTION}

Odontomas are the most common benign odontogenic tumors of epithelial and mesenchymal origin and characterized by their slow growth. ${ }^{1,2}$ Odontomas account for $22 \%$ of all odontogenic tumors of the jaws. ${ }^{3}$ Odontomas are hamartomas composed of various dental tissues, i.e., enamel, dentin, cementum and sometimes pulp are arranged as they would be in the normal tooth. ${ }^{2,4}$ According to the 1992 classification of the World Health Organization (WHO), two types of odontomas (complex and compound) are acknowledged ${ }^{1}$ : complex odontomas, a

\author{
Şeref EZIRGGANLI \\ Bezm-i Alem University \\ Faculty of Dentistry, \\ Department of Oral and Maxillofacial Surgery, \\ İstanbul, Turkey \\ e-mail: seref.ezirganli@gmail.com
}

This study was presented as a poster presentation at $4^{\text {th }}$ AÇBID International Oral \& Maxillofacial Surgery Society Congress, 26-30 May, 2010, Antalya, Turkey. malformation in which all dental tissues are well formed but occurring in a less orderly pattern; and compound odontomas, a malformation in which all of the dental tissues are arranged in a more orderly fashion than in the complex type, so that the lesion consists of many tooth-like structures. ${ }^{5}$ These lesions are normally diagnosed by routine radiological studies. Radiologically, odontomas manifest as a dense radiopaque lesion surrounded by a thin radiotransparent halo. ${ }^{1}$ While the complex type is more common in the posterior region of the lower jaw, the compound type is more frequently found in the anterior region of the maxilla. ${ }^{6}$ Compound odontomas are more prevalent than complex odontoma, and most such lesions are asymptomatic. ${ }^{7,8}$

Their etiology is completely unknown, but local trauma, infection, and genetic characteristics are suggested as possible factors. ${ }^{6}$ Odontomas are treated by conservative surgical removal and there is little probability of recurrence. ${ }^{5}$ 


\section{CASE REPORT}

A 12-year-old-female patient was referred to our clinic due to the failure of the right mandibular central tooth to erupt and pain at the anterior mandibular region. There was a history of trauma, although no deformations or swelling of the maxillofacial region. A clinical examination revealed no facial asymmetry extra orally, but it seemed there were no right mandibular incisors during the intra oral examination. It was determined that the patient had experienced pain for about two months at the anterior mandible, and her decidious lateral incisor had been removed due to a sports-related injury when she was 4 years old. A right mandibular central incisor in the vertical position and covered with multiple radioopaque structures was determined to be present through panoramic and periapical radiographs (Figure 1) and extracted in a surgical operation. It was established that the central incisor had many tooth-like structures after the surgical operation (Figure 2). The initial radiographic diagnosis was a compound odontoma, and it was also confirmed histopathologically (Figure 3). The patient was advised to come to our clinic if any complication occurred, such as pain or swelling.
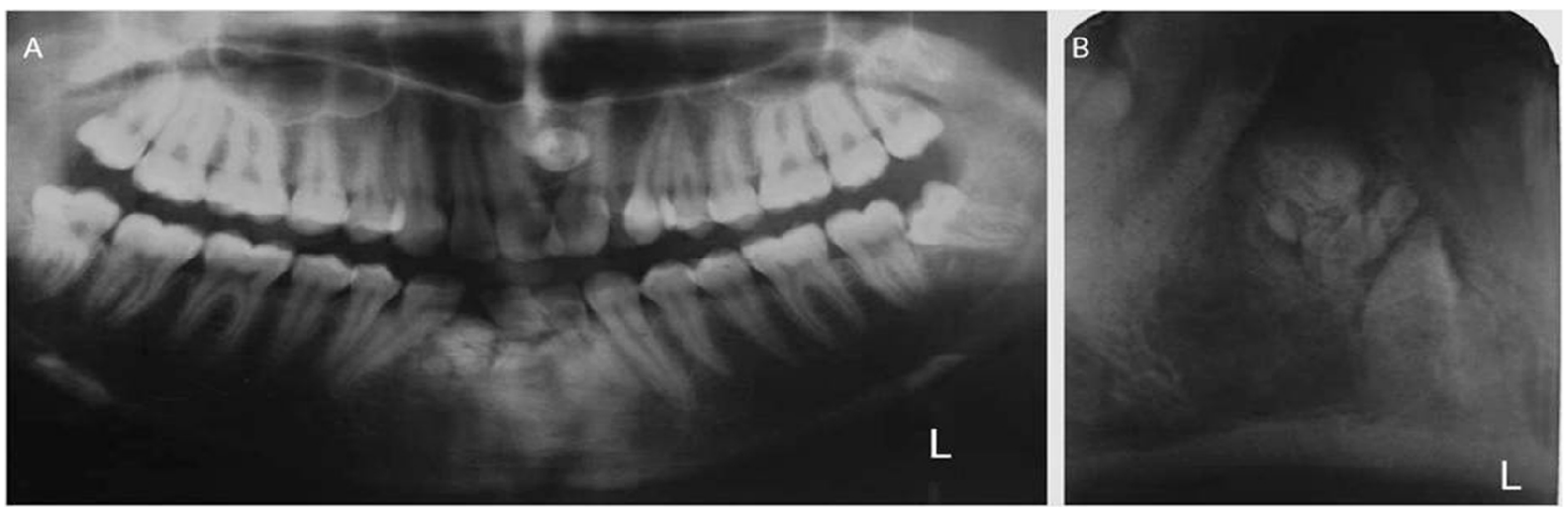

Fig 1. A: Initial Panoramic radiograph.

B: A periapical radiograph showing the odontoma and the impacted mandibular central tooth.
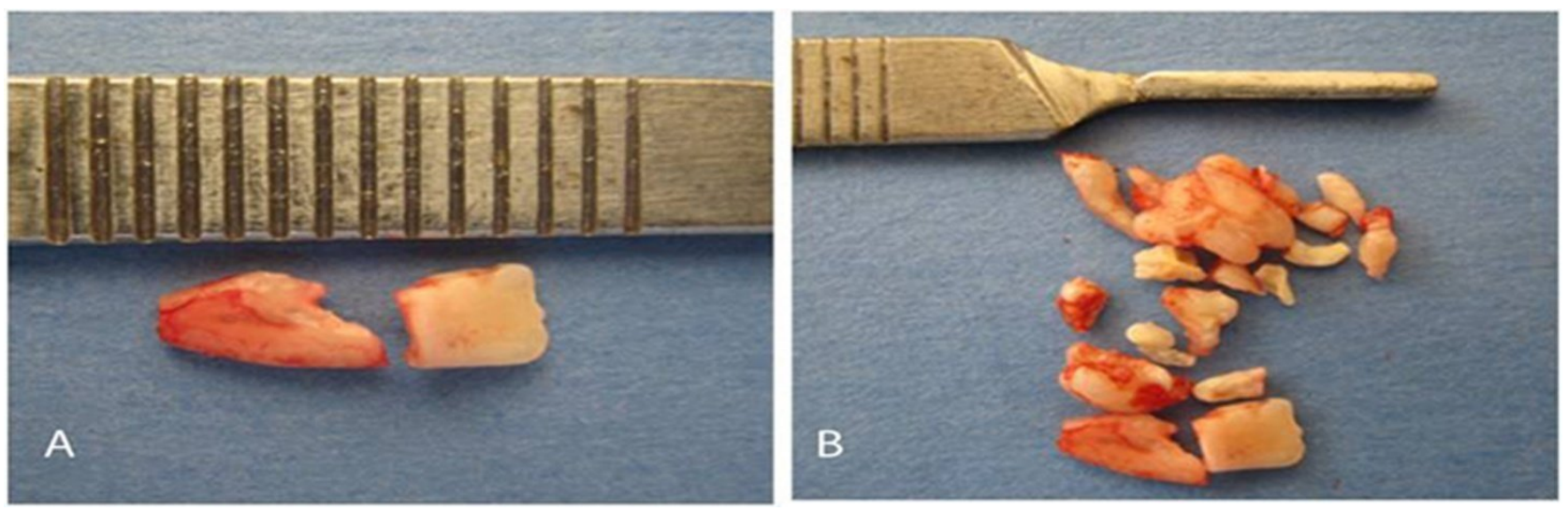

Fig 2. A: Mandibular central tooth.

B: The view of the calcified masses and mandibular central tooth, which were removed from the surgical site. 


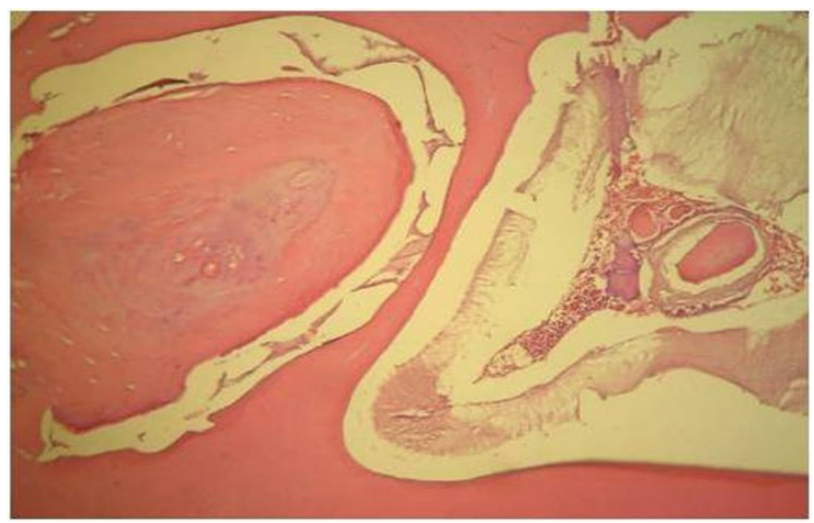

Fig 3. Photomicrograph of extracted tissue (H \& E stain, X100)

\section{DISCUSSION}

Odontoma is the most common type of odontogenic tumor, though some authors prefer to refer to it as hamartoma, not a true tumor. It was first described by Paul Broca in 1867. ${ }^{3,4}$ Odontomas was classified as either complex or compound by the WHO in $1992 .^{1,2}$ Complex odontomas are twice as less common than the compound. ${ }^{4}$ Compound odontoma is a malformation in which all the dental tissues are arranged in a more orderly pattern than in complex odontoma, so that the lesion consists of many tooth-like structures. ${ }^{5}$ In this case, it seemed that after the operation, the patient had a lot of tooth-like structures with an impacted central incisor because of trauma.

Odontomas are discovered by routine radiography, but sometimes may cause difficulty in identification due to lack of calcification. Radiographically, compound odontomas typically manifest as a dense radiopaque lesion surrounded by a thin radiotransparent halo. Three developmental stages (radiotransparency, intermediate and radiopaque stage) can be identified, based on the radiological features and degree of calcification of the lesion at the time of diagnosis. At the first stage, dental tissue calcification is absent. The second or intermediate stage presents partial calcification. The third or classically radiopaque stage exhibits predominant tissue calcification with the previously mentioned surrounding radiotransparent halo. ${ }^{1-9}$

The etiology of these lesions is still exactly unknown but local trauma, infection, inheritance and/or genetic mutation factors have been suggested. ${ }^{3-6,9}$ In this case, the reason for odontoma is believed to be the childhood trauma. The etiological factors of dental retention are possible ectopic tooth development, ectopic tooth eruption, premature apical closure, unfavorable tooth rotation, altered eruption sequence, premature loss of deciduous tooth, supernumerary tooth, presence of tumor as odontomas, presence of cyst, inadequate space in the dental arch and sequelae of oral trauma. ${ }^{6}$ In the present case, possible reasons for permanent lateral incisor retention may be the presence of compound odontoma, trauma history, premature loss of lateral incisor and unfavorable tooth rotation.

These lesions (compound odontomas) are usually more common in the anterior maxilla (61\%), in male patients and usually found in the second decade of life. ${ }^{4,5,9} \mathrm{In}$ this case, the patient was a 12-year-old female and the lesion was found in the anterior mandible. If there is the absence of any contraindication, the treatment for odontomas is a surgical excision with complete enucleation and curettage of the odontoma site. Recurrences are uncommon. ${ }^{4-6,9}$ 


\section{CONCLUSION}

In conclusion, this case report is important according to diagnosis and treatment of compound odontomas. If there is absence of any contraindication, the treatment for odontomas is surgical excision.

\section{REFERENCES}

1. Amado CS, Gargallo Albiol J, Berini AL, Gay EC. Review of 61 cases of odontoma. Presentation of an erupted complex odontoma. Med Oral 2003;8:366-373.

2. Amailuk P, Grubor D. Erupted compound odontoma: Case report of a 15-year-old Sudanese boy with a history of traditional dental mutilation. Br Dent J 2008;204:1114. [CrossRef]

3. Cildir SK, Sencift K, Olgac V, Sandalli N. Delayed eruption of a mandibular primary cuspid associated with compound odontoma. J Contemp Dent Pract 2005;6:152159.

4. Vengal M, Arora H, Ghosh S, Pai KM. Large erupting complex odontoma: a case report. J Can Dent Assoc 2007;73:169-173.
5. Zoremchhingi, Joseph $\mathrm{T}$, Varma B, Mungara J. A compound composite odontoma associated with unerupted permanent incisor: A case report. $\mathrm{J}$ Indian Soc Pedod Prev Dent 2004;22:114-117.

6. Da Costa CT, Torriani DD, Torriani MA, da Silva RB. Central incisor impacted by an odontoma. J Contemp Dent Pract 2008;9:122128.

7. Hidalgo-Sánchez O, Leco-Berrocal MI, Martínez-González JM. Metaanalysis of the epidemiology and clinical manifestations of odontomas. Med Oral Patol Oral Cir Bucal 2008;13:730-734.

8. Özan F, Yeler H, Yeler D. Mandibular gömülü daimi kanin diş ile ilișkili süpernümerer diș ve kompaund odontoma: vaka raporu. Atatürk Üniv Diş Hek Fak Derg 2005;15:61-64.

9. Shelton JT, Owens BM, Schuman NJ. Compound odontoma associated with an impacted permanent central incisor. J Tenn Dent Assoc 1997;77:46-48. 